\title{
References
}

1. Freeman A, Geddes N, Munson P, Joseph J, Ramani P, Sandison A, et al.: Anaplastic lymphoma kinase (ALK 1) staining and molecular analysis in inflammatory myofibroblastic tumours of the bladder: a preliminary clinicopathological study of nine cases and review of the literature. Mod Pathol. 2004; 17: 765-71.

2. Billis A: Weekly conference with the residents. Case 21. Available: http://www.fcm.unicamp.br/deptos/anatomia/ casosdeuro/casosdeuroentrada.html.

3. Tsuzuki T, Magi-Galluzzi C, Epstein JI: ALK-1 expression in inflammatory myofibroblastic tumor of the urinary bladder. Am J Surg Pathol. 2004; 28: 1609-14.

Dr. Athanase Billis

Full-Professor of Pathology

State University of Campinas, Unicamp

Campinas, Sao Paulo, Brazil

\section{INVESTIGATIVE UROLOGY}

\section{Testicular Volume Measurement: Comparison of Ultrasonography, Orchidometry, and Water Displacement}

Sakamoto H, Saito K, Oohta M, Inoue K, Ogawa Y, Yoshida H

Department of Urology, Showa University School of Medicine, Tokyo, Japan

Urology. 2007; 69: 152-7

Objectives: To determine the accuracy of orchidometry and ultrasonography for measuring the testicular volume by comparing the resultant measurements with the actual testicular volume in humans.

Methods: The testicular volume of 40 testes from 20 patients with prostate cancer (mean age +/- SD 74.5 +/- 7.5 years) was measured using the Prader orchidometer and ultrasonography before therapeutic bilateral orchiectomy. The ultrasound measurements of testicular volume were calculated using three formulas: length (L) $\mathrm{x}$ width (W) $x$ height $(\mathrm{H}) \times 0.52$, $\mathrm{L} \times \mathrm{W} 2 \times 0.52$, and $\mathrm{L} \times \mathrm{W} \times \mathrm{H} \times 0.71$. The actual testicular volumes were determined by water displacement of the surgical specimen.

Results: The mean actual testicular volume of the 40 testes was $9.3 \mathrm{~cm} 3$ (range 2.5 to 23.0). A strong correlation was found between the testicular volume calculated by the three ultrasound formulas and the actual volume ( $\mathrm{r}$ $=0.910$ to $0.965, \mathrm{P}<0.0001)$ and was stronger than the correlation with the Prader orchidometer $(\mathrm{r}=0.818, \mathrm{P}$ $<0.0001)$. The smallest mean difference from the actual testicular volume was observed with the formula $\mathrm{Lx} \mathrm{W}$ x $\mathrm{H}$ x 0.71 , which overestimated the actual volume by $0.80 \mathrm{~cm} 3(7.42 \%)$. The measurements using the Prader orchidometer correlated with the actual testicular volume and with the testicular volume calculated using the three ultrasound formulas ( $\mathrm{r}=0.801$ to $0.816, \mathrm{P}<0.0001)$. However, the orchidometer measurements had the largest mean difference from the actual testicular volume $(6.68 \mathrm{~cm} 3,81.7 \%)$.

Conclusions: The results of this study have shown that measuring the testicular volume by ultrasonography is more accurate than by the Prader orchidometer, and the formula $\mathrm{L}$ x W x H x 0.71 was the most accurate for calculating the testicular volume.

\section{Editorial Comment}

This is a straightforward research work, which objectively demonstrates that ultrasonographic evaluation of testicular volume is accurate. The authors compared ultrasound evaluation by the ellipsoid volume formula ( 2 
methods), a variation of the ellipsoid formula and orchidometry, with water displacement, that is the real volume (Laplace principle). Although the classical ellipsoid volume formula used in ultrasound equipment is accurate, the authors demonstrated that the best formula is a variant of the ellipsoid formula, called the Lambert empiric formula $(\mathrm{V}=$ Length $\times$ Width $\times$ Height $\times 0.71)$.

Dr. Francisco J.B. Sampaio

Full-Professor and Chair, Urogenital Research Unit

State University of Rio de Janeiro

Rio de Janeiro, RJ, Brazil

\section{Immediate Improvement in Penile Hemodynamics after Cessation of Smoking: Previous Results} Sighinolfi MC, Mofferdin A, De Stefani S, Micali S, Cicero AF, Bianchi G

Department of Urology, University of Modena, Modena, Italy

Urology. 2007; 69: 163-5

Objectives: To assess the chronologic relationship between the cessation of smoking and the restoration of erectile function. Smoking is associated with an increased risk of erectile dysfunction.

Methods: Twenty active smokers (20 to 40 cigarettes/day) affected by erectile dysfunction (International Index of Erectile Function 5-item score less than 21) were enrolled in the study. The mean age was 40 years. All the patients underwent penile color Doppler ultrasonography during the basic and dynamic phases (10 microg prostaglandin E1). A second Doppler evaluation was performed 24 to 36 hours after cessation of smoking. The peak systolic velocity (PSV) and end-diastolic velocity (EDV) were recorded. The PSV and EDV cutoff value was $30 \mathrm{~cm} / \mathrm{s}$ and $5 \mathrm{~cm} / \mathrm{s}$, respectively.

Results: Of the 20 patients, 10 (50\%) had normal PSV values but only $5(25 \%)$ had normal EDV values at the baseline Doppler evaluation. All the patients $(100 \%)$ had normal PSV values at the second penile Doppler evaluation after smoking withdrawal, and 17 (85\%) also had normal EDV values. The average PSV was 40.1 and $50.3 \mathrm{~cm} / \mathrm{s}(\mathrm{P}=0.09)$ and the mean EDV was 6.8 and $2.4 \mathrm{~cm} / \mathrm{s}(\mathrm{P}<0.01)$ at the baseline penile Doppler examination and after smoking withdrawal, respectively.

Conclusions: Within 24 to 36 hours of the cessation of cigarette smoking, the color Doppler parameters demonstrated a significant improvement in EDV and a trend toward an increase in PSV. Additional clinical evaluation is required to further characterize the expeditious improvement in erectile function after the cessation of smoking.

\section{Editorial Comment}

This is a very impressive study, on which the authors evaluated prospectively 20 current smokers (20 to 40 cigarettes/day) with a mean of 7 years of smoking history. It was found that after 24 to 36 hours of smoking cessation, all 20 patients (100\%) had normal peak systolic velocity values and 17 (85\%) had normal enddiastolic velocity values at Doppler examination. This study is pioneer on the evaluation of short-term effects of the cessation of cigarette smoking in penile hemodynamics parameters. It is impressive how rapidly smoking cessation can improve penile hemodynamics.

Dr. Francisco J.B. Sampaio

Full-Professor and Chair, Urogenital Research Unit

State University of Rio de Janeiro

Rio de Janeiro, RJ, Brazil 


\section{Effect of Extract of Phyllanthus Niruri on Crystal Deposition in Experimental Urolithiasis} Barros ME, Lima R, Mercuri LP, Matos JR, Schor N, Boim MA Department of Medicine, Renal Division, Federal University of Sao Paulo, Sao Paulo, SP, Brazil Urol Res. 2006; 34: 351-7

Phyllanthus niruri $(\mathrm{Pn})$ is a plant that has been shown to interfere in the growth and aggregation of calcium oxalate $(\mathrm{CaOx})$ crystals. In the present study we evaluated the effect of $\mathrm{Pn}$ on the preformed calculus induced by introduction of a $\mathrm{CaOx}$ seed into the bladder of male Wistar rats. Pn treatment $(5 \mathrm{mg} / \mathrm{rat} / \mathrm{day})$ was initiated immediately or 30 days after $\mathrm{CaOx}$ seeding and thus in the presence of a preformed calculus. Animals were sacrificed 50 or 70 days after surgery. The resulting calculi were weighed and analyzed by X-ray diffraction, stereomicroscopy and scanning electronic microscopy. Precocious Pn treatment reduced the number $(75 \%, \mathrm{P}<$ $0.05)$ and the weight $(65 \%, \mathrm{P}<0.05)$ of calculi that frequently exhibited a matrix-like material on its surface, compared to the untreated $\mathrm{CaOx}$ group. In contrast, $\mathrm{Pn}$ treatment in the presence of a preformed calculus did not prevent further calculus growth; rather, it caused an impressive modification in its appearance and texture. Calculi from Pn-treated animals had a smoother, homogeneous surface compared to the spicule shape of calculi found in the untreated $\mathrm{CaOx}$ group. XRD analysis revealed the precipitation of struvite crystals over the $\mathrm{CaOx}$ seed and Pn did not change the crystalline composition of the calculi. This suggests that Pn interfered with the arrangement of the precipitating crystals, probably by modifying the crystal-crystal and/or crystal-matrix interactions. Results suggest that Pn may have a therapeutic potential, since it was able to modify the shape and texture of calculi to a smoother and probably more fragile form, which could contribute to elimination and/or dissolution of calculi.

\section{Editorial Comment}

Phyllanthus niruri, is a plant used in Brazilian folk medicine. Its infusion tea is called "break-stone tea" and is widely used in Brazil for treatment of urolithiasis. The authors of this paper have been studying the effects of Phyllanthus niruri on urolithiasis at least for the last 10 years and have contributed a lot for the specialized literature (1-3).

In the present experimental study, the authors used a model of preformed calculus induced by introduction of a $\mathrm{CaOx}$ seed into the bladder of male Wistar rats. The authors elegantly demonstrated, by using X-ray diffraction, stereomicroscopy and scanning electronic microscopy, that precocious treatment with Phyllanthus niruri significantly reduced the number and the weight of calculi compared to the untreated $\mathrm{CaOx}$ seeding group. Also, on scanning electronic microscopy, in treated group, it was observed a homogeneous surface compared to the spicule shape of calculi found in the untreated $\mathrm{CaOx}$ group. These findings, together with previous findings from the same research group (1-3), suggest objectively that Phyllanthus niruri ("break-stone tea") might have therapeutic potential for urolithiasis.

Interesting, in a recent published work from Italy, it was assessed the efficacy of Phyllanthus niruri after extracorporeal shock wave lithotripsy (ESWL) for renal stones (4). The authors evaluated prospectively 150 patients with renal stones that were as large as $25 \mathrm{~mm}$ and composed of calcium oxalate. All patients received 1 to 3 ESWL with Dornier Lithotriptor S. After treatment, 78 of 150 patients (52\%) underwent therapy with Phyllanthus extract for at least 3 months (group 1). The other 72 of 150 patients (48\%) were used as a control group (group 2). No significant difference in stone size between the 2 groups was found. Stone clearance was assessed after 30, 60, 90 and 180 days by abdominal X-ray and ultrasonography. Although no significant difference was found at the end point of the follow-up (180 days), for lower caliceal stones (56 patients) the stone-free rate was $93.7 \%$ in the treatment group and $70.8 \%$ in the control group $(p=0.01)$. The authors concluded that regular self-administration of Phyllanthus niruri after ESWL for renal stones results in an increased stone-free rate that appears statistically significant for lower caliceal location. Since ESWL for lower pole 
stones is challenging and present poor results when compared to other locations stones (5), the efficacy and the lack of side effects make Phyllanthus niruri therapy suitable to improve overall outcomes after extracorporeal shock wave lithotripsy for lower pole stones.

\title{
References
}

1. Barros ME, Schor N, Boim MA: Effects of an aqueous extract from Phyllanthus niruri on calcium oxalate crystallization in vitro. Urol Res. 2003; 30: 374-9.

2. Freitas AM, Schor N, Boim MA: The effect of Phyllanthus niruri on urinary inhibitors of calcium oxalate crystallization and other factors associated with renal stone formation. BJU Int. 2002; 89: 829-34.

3. Campos AH, Schor N: Phyllanthus niruri inhibits calcium oxalate endocytosis by renal tubular cells: its role in urolithiasis. Nephron. 1999; 81: 393-7.

4. Micali S, Sighinolfi MC, Celia A, De Stefani S, Grande M, Cicero AF, et al.: Can Phyllanthus niruri affect the efficacy of extracorporeal shock wave lithotripsy for renal stones? A randomized, prospective, long-term study. J Urol. 2006; 176: 1020-2.

5. Sampaio FJ: Renal collecting system anatomy: its possible role in the effectiveness of renal stone treatment. Curr Opin Urol. 2001; 11: 359-66.

Dr. Francisco J.B. Sampaio Full-Professor and Chair, Urogenital Research Unit State University of Rio de Janeiro Rio de Janeiro, RJ, Brazil

\section{RECONSTRUCTIVE UROLOGY}

\author{
Efficacy of the InVancetrade mark Male Sling in Men with Stress Urinary Incontinence \\ Fassi-Fehri H, Badet L, Cherass A, Murat FJ, Colombel M, Martin X, Gelet A \\ Department of Urology and Transplantation, Edouard Herriot Hospital, Lyon, France \\ Eur Urol. 2007; 51: 498-503
}

Objectives: To evaluate the efficacy and safety of the InVancetrade mark bulbourethral sling in male stress urinary incontinence.

Materials and Methods: Between June 2003 and April 2005, the InVancetrade mark bulbourethral sling was implanted into 50 patients with urinary incontinence after prostate surgery in 49 cases and pelvic trauma in 1 case. The patients were monitored and evaluated in a prospective manner (continence, tolerance, and satisfaction). The treatment was considered to be successful if the patient stopped wearing any kind of continence pad (patient cured) or only one pad per day (patient improved), with no de novo urinary disorders and without significant postvoid residual urine. Patient satisfaction with the procedure was assessed.

Results: After a median follow-up of 6 mo, 50\% of patients were dry, 26\% had improved, and 24\% suffered treatment failure. The success rates for the patients with severe incontinence and those who had undergone radiation therapy were $50 \%$ and $25 \%$, respectively. All patients who were dry or had improved were satisfied and presented no obstructive or irritative de novo urinary disorders. The overall success rate for the 51 procedures conducted was $74.5 \%$. Six cases of transitory acute urine retention and six cases of persistent perineal pain were reported. Explantation was necessary because of suppuration of the sling in three patients and of a de novo irritative urinary disorder in one patient. No cases of pubic osteitis or urethral erosion were reported. 